\title{
Understanding Contrasting Approaches to Nationwide Implementations of Electronic Health Record Systems: England, the USA and Australia
}

\author{
Zoe Morrison, MSc ${ }^{1 *}$; Ann Robertson, $\mathrm{PhD}^{1}$; Kathrin Cresswell, $\mathrm{MSc}^{1}$; \\ Sarah Crowe, PhD $^{2}$; Aziz Sheikh, FRCP ${ }^{1}$ \\ ${ }^{1}$ eHealth Research Group, Centre for Population Health Sciences, \\ The University of Edinburgh, $U K$ \\ ${ }^{2}$ School of Community Health Sciences, University of Nottingham, UK
}

Submitted July 2010. Accepted for publication November 2010.

\begin{abstract}
As governments commit to national electronic health record (EHR) systems, there is increasing international interest in identifying effective implementation strategies. We draw on Coiera's typology of national programmes - 'top-down', 'bottom-up' and 'middle-out' - to review EHR implementation strategies in three exemplar countries: England, the USA and Australia. In comparing and contrasting three approaches, we show how different healthcare systems, national policy contexts and anticipated benefits have shaped initial strategies. We reflect on progress and likely developments in the face of continually changing circumstances. Our review shows that irrespective of the initial strategy, over time there is likely to be convergence on the negotiated, devolved middle-out approach, which aims to balance the interests and responsibilities of local healthcare constituencies and national government to achieve national connectivity. We conclude that, accepting the current lack of empirical evidence, the flexibility offered by the middle-out approach may make this the best initial national strategy.
\end{abstract}

Keywords: electronic health records, implementation, information technology, international approaches

\section{INTRODUCTION}

The implementation of electronic health record (EHR) systems is now being pursued around the world in an attempt to improve the quality, safety and efficiency of affordable healthcare. Historically, these have tended to be small-scale implementations, taking

*Corresponding Author:. Zoe Morrison, Centre for Population Health Sciences, Medical School, The University of Edinburgh, Room 112, Doorway One, Teviot Place, Edinburgh, EH8 9AG. UK. Phone: +44 (0)131651 4151. Fax: +44 (0)131650 9119. E-mail: zoe.morrison@ed.ac.uk.

Other authors: A.R.R.Robertson@ed.ac.uk; Kathrin.Beyer@ed.ac.uk; Sarah.Crowe@nottingham.ac.uk; aziz.sheikh@ed.ac.uk. 
place in one or at most a handful of healthcare settings [1-3]. More recently, however, there has been an increasing drive to deliver much more substantial, national-level implementations of EHRs. Early evidence from national implementation programmes suggests that the problems associated with introducing EHRs on a small, local scale may be magnified several-fold in larger-scale implementations [4]. Hence, there is a need to maximise understanding of the approaches that are being taken to implement EHR systems nationally [5], the rationale for choosing one implementation approach over another and early lessons that can be drawn from international experiences.

In this paper, we employ the typology that Coiera constructed to explore national EHR implementation approaches using his exemplar countries of England, the USA and Australia [6]. We consider salient aspects of each of these countries' healthcare systems and the policy contexts that have shaped the initial choices about EHR system procurement and implementation, the actual approaches being pursued and the progress made to-date. Importantly, however, we seek to go beyond a detailed description of the experiences of deploying EHR systems to understand why a particular national implementation approach was initially adopted and how, if at all, this has needed to evolve in the light of early experiences and changing circumstances. We report that these three countries' approaches are now converging on what Coiera described as the middle-out approach, and consider the implications of the review for future work.

\section{APPROACHES TO IMPLEMENTING NATIONAL EHR SYSTEMS}

The envisaged benefits of national EHR systems include increased efficiency in healthcare organisation and delivery through (i) improved data sharing, (ii) improved data quality, security and availability, (iii) reduced errors, (iv) patient empowerment, and (v) time-savings for staff $[7,8]$. However, even on a small scale, the limited literature available suggests that, in practice, attempts to implement EHR systems in healthcare settings frequently encounter difficulties [9-13]. The reasons for these difficulties are typically multi-faceted, most often resulting from a complex interplay between organisational, social and technical factors. In essence, however, they often reflect a failure to appreciate fully the disruptive nature of new IT systems, which can alter many aspects of healthcare professionals' routine working practices and patients' experience of care [14].

National governments have priority areas for EHR implementations and the associated hoped-for benefits. Some countries have concentrated on unscheduled care (e.g., Scotland and the Netherlands), others on primary care (e.g., Denmark, New Zealand and Spain), while the focus elsewhere includes secondary care (e.g., England and China) [15-20]. There are also important variations in the national approach to achieving the exchange of healthcare information, for which some have advocated systems standardisation (e.g., England) whereas others plan to use interoperability standards for the integration of existing and new IT systems (e.g., Canada and Hong Kong) [21].

Using a socio-technical framework, Coiera's work [6] offers a useful theoretical lens through which to view different national approaches. His typology differentiates 
between three broad approaches to national EHR implementations, which he categorises as 'top-down', 'bottom-up' and 'middle-out'. A top-down approach is directed by government, with the central procurement of standardised healthcare IT systems to replace existing diverse systems and the aim of centrally stored and shared EHRs. He gave England's National Programme for Information Technology (NPfIT) as an exemplar of this approach [6]. In contrast, the bottom-up model relies on local healthcare organisations taking responsibility for making their existing and any newly acquired healthcare IT systems compliant with interoperability standards. Multiple EHRs are held locally, but the intention is that data will become accessible from other settings as diverse local systems become integrated over time. Coiera presented the USA as an example of this approach [6]. The middle-out approach has elements of both the top-down and bottom-up strategies. It combines local consultation, systems choice and investment with central government support and nationally agreed interoperability standards and goals. Local healthcare providers retain responsibility for choosing their EHR systems and for complying with national standards in order to exchange information with other healthcare providers. Coiera identified the then Australian strategy of focusing on standards rather than government implementations of IT as an example of the middle-out approach [6].

In considering these three countries as exemplars of different national approaches, Coiera suggested that the USA and England initially chose diametrically opposed approaches, each of which was likely to have undesirable consequences (such as uncertainties about achieving data exchange in the first instance, and uncertainties about clinician acceptance and use in the second). Australia's approach was an example of a middle way between the two, with arrangements that required compromise and consensus to balance local freedoms and constraints in order to have shareable digital information. Coiera proposed that an initial implementation approach could migrate to a different approach during the lifetime of a national programme [6]. As an advocate of the middle-out approach, he suggested that both the USA and England might consider moving towards a middle-out approach over time in order to achieve functional, national EHR systems.

\subsection{England}

In England, the initial intention was to deliver standardised EHR applications, organised through a central implementation agency, National Health Service Connecting for Health (NHS CFH); thus the national strategy was top-down [6]. Local NHS organisations (Trusts) were to adhere to the national programme rather than buying or developing their own solutions for EHRs. The underlying premise was that rigorous standardisation and centrally procured systems would rapidly lead to national connectivity in the most cost-effective way. However, the sheer scale of England-wide deployments and variations in the functionalities of the national applications, together with the diversity of multiple stakeholders' interests, Trusts' variable readiness for change and problems arising from centrally negotiated, long-term contracts, have, among other factors, contributed to deployment delays and to more localised approaches emerging [4]. Coiera [6] noted that implementation approaches might 
change over time. This has certainly been the case in England, where the top-down, centrally driven implementation of EHRs has been evolving into more localised solutions. For example, after a standardised Cerner Millennium application had been implemented in the Royal Free Hampshire NHS Trust in London - and had resulted in disruption to care delivery and loss of Trust income - a "new delivery model" was agreed for secondary care in London to allow for some local tailoring of the standard application.

\subsection{USA}

In the USA, centrally funded incentives to ensure some basic standards of interoperability rely on the implementation and use of locally chosen systems. Federal government's role has been demonstrated by government policy objectives, strategies and actions relating to data privacy and security, interoperability, adoption and collaborative governance [22]. In contrast to the English approach, there was a strongly stated commitment from the start to encourage multiple stakeholders, including patients, to become 'active participants' in the policy development process at local, state and federal levels. The security model adopted was also significantly different from that in England. While England had one centrally directed model for protecting data confidentiality, the aim in the USA was for all stakeholders to become better informed about patient preferences in relation to privacy and security policies, which differed across states and organisations. It was felt that a lack of support from any of the major stakeholder groups could lead to solutions that only worked for some, or could actually halt progress with implementing EHRs.

An important potential barrier to EHR implementation in the USA is the risk of purchasing a product locally that does not allow for data exchange between different care settings [23]. In an attempt to address this, the Certification Commission for Health Information Technology (CCHIT) developed a set of certification criteria through a voluntary, consensus-based process engaging diverse stakeholders [24]. This independent, not-for-profit organisation, founded in 2004, was recognised as a

certifying body by the Department of Health and Human Services (HHS) and tasked with prioritising and developing criteria for different areas of healthcare, such as inpatient care, emergency departments and ambulatory EHRs. By mid-2009, more than 200 EHRs had been certified by the CCHIT, which represented 75\% of the EHR marketplace [24]. Certification involved inspection of an EHR's integrated functionality, interoperability and security [24]. In the same year, the Office of the National Coordinator for Health Information Technology authorized the establishment of "Testing and Certification Bodies" (of which the CCHIT was one) to test and certify EHR technology compliance with the certification criteria, standards and implementation specifications adopted by the HHS. The Health Information Technology for Economic and Clinical Health Act (HITECH) tied the certification to standards and implementation specifications and to financial incentives offered under the Medicare and Medicaid EHR programmes [23]. These standards and specifications are known as the 'Meaningful Use Criteria'. The HHS announced grants of more than $\$ 1$ billion to 56 states and 60 Regional Extension Centers (RECs) to support the 
development of health information exchanges and provide technical assistance to help healthcare providers select, implement and use certified EHR technology [25].

However, both the American Medical Association (AMA) and American Hospital Association (AHA) have expressed concerns that the costs of EHR systems and meeting the requirements needed to qualify for the incentive payments might be out of reach for many American physicians and hospitals. In a letter to the National Coordinator for Health Information Technology in March 2010, the AHA's expressed concerns included setting "rational" implementation timelines, such that finalised certification criteria were available at least three years before hospitals had to comply to qualify for incentive payments: "Insufficient lead time for implementation, product development and certification places an unfair burden on hospitals and eligible professionals, raising implementation costs and potentially jeopardizing patient safety" [26]. While similarly broadly supportive of moves to develop and implement healthcare IT, the concerns of the AMA have focused on the privacy of EHRs and local implementation costs. Large healthcare practices and hospitals could afford EHRs but many smaller ones - which were in the majority - could not [27]. Such concerns were echoed in a recent study highlighting that only two per cent of USA hospitals reported having records that currently met the national Meaningful Use Criteria [28].

\subsection{Australia}

In Australia, a new programme for Internet-based Person-Controlled Electronic Health Records (P-CEHRs) is the most recent in a series of Australian government initiatives for healthcare IT. At the start of this decade, a top-down MediConnect programme (which was itself based on the earlier Better Patient Medication Management System) had been intended to provide an Australia-wide, secure electronic system for medication management. MediConnect was incorporated into another programme, HealthConnect, in 2004. HealthConnect was conceived as a national change management strategy, and was to include a move from paper-based records to standardised, digital patient records held at the point of care. In the current P-CEHR plan, it is envisaged that from 2012/13, those patients who wish will have a secure access point (portal) through which to view information about themselves, stored on their various healthcare providers' IT systems [29]. This P-CEHR webpage will show a health summary, containing the individual's demographic information, medical conditions, medications and any allergies. It is also planned to show an index and searching function for accessing a range of personal healthcare information, such as referrals, test results and prescriptions. Access to summaries of detailed, personal information is expected to increase over time as more healthcare providers implement and adopt P-CEHR system data exchange functionality.

The approach to implementing the EHR system in Australia may therefore be described as incremental, with P-CEHRs to become progressively available from 2012/13 onwards [30]. Government investment and support for national infrastructure, governance, standards development and tools are to be combined with local choice and responsibility for compatible, clinical IT systems, exemplifying Coiera's middle-out approach (6). The National E-Health Transition Authority (NEHTA) was set up in 2005 
to drive the approach and "... coordinate the progression and accelerate the adoption of e-health by delivering urgently needed integration infrastructure and standards for health information" [31]. NEHTA also leads the development of a security framework to control authorised access to data. A primary task for NEHTA now is to continue to lead collaborative work with stakeholders to develop the national standards that will be necessary to achieve interoperability between diverse, existing and new clinical systems.

\section{UNDERSTANDING FACTORS THAT HAVE SHAPED IMPLEMENTATION STRATEGIES}

\subsection{Healthcare Systems: the Wider Context of Implementation and Existing Structures}

The NHS in England is run by the Department of Health (DH) and funded by taxpayers' money. It was established in 1948 to provide universal access to care that is free for all at the point of delivery. Notions of equality and social justice are thus part of the NHS ethos and lead to value being placed on consistency of NHS care. However, successive governments' policies have resulted in complex, devolved governance and funding structures, including the introduction of internal markets within the national organisation [32]. Today's NHS is thus highly fragmented, consisting of a variety of diverse, and to some extent autonomous, organisations that may be at once in competition and collaboration with one another [33]. The NHS is also tasked with making significant 'efficiency savings' in the current UK economic climate, and now faces further organisational restructuring under new plans announced by the present government [34].

In contrast to the English NHS, the healthcare system in the USA is funded commercially by a combination of private and federal medical insurance schemes. More money is spent per capita on healthcare in the USA than in any other nation in the world [35]. The majority of hospitals in the USA are not-for-profit institutions [38], although the number of investor-owned (for-profit) hospitals has risen [39;40]. With 45.7 million people uninsured at some time in 2007 [36], the ongoing debate on healthcare reform in the USA centres on whether there is a fundamental right to healthcare, and whether the government should compel citizens to buy insurance or pay a healthcare tax. This debate has formed a focus of attention in the early days of the Obama presidency. His controversial Healthcare Reform Bill, passed by Congress on $21^{\text {st }}$ March 2010, provides near universal healthcare coverage to Americans and has been seen as a 'massive change in US healthcare provision' extending coverage to an additional 32 million people [37].

In Australia, the healthcare system has historically been a complex mixture of public and private services rather than a nationally integrated healthcare system. There are both Commonwealth government and state government funded health services, and private health services funded through private health insurance. The Commonwealth government encourages people to take out private health insurance, but also provides a universal health insurance scheme, Medicare, which is partially funded by an income tax surcharge. Since 1984, this scheme has made free, or subsidised, public hospital 
treatment available to Australian residents, who also have access to subsidised prescription medicines through a national Pharmaceutical Benefits Scheme (PBS).

\subsection{Policy Drivers}

While the different histories, cultures, funding structures, ethos and political positions of healthcare services all influence national policy objectives, each of our three exemplar countries shares the healthcare challenges presented by ageing populations, the increasing prevalence of long-term conditions and significant health inequalities among their populations with respect to accessing services and health outcomes. National EHR programmes in England, the USA and Australia have thus all originated as part of wider political visions of creating improved and sustainable healthcare systems, underpinned by nationwide health IT infrastructures to increase quality and safety of care, service access and the sharing of information across organisational boundaries. A summary of milestones in the development of the three national strategies and the associated policy documents is given in Table 1. While we acknowledge prior strategies (such as a call for legislation to facilitate the implementation and dissemination of the computer-based patient record in the USA [41], and the earlier, top-down healthcare IT programme, MediConnect, in Australia), here we note England's 1998 announcement of plans for a national implementation of EHRs as the beginning of the development of the national implementation approaches discussed in this paper.

In both England and the USA, EHR implementation was planned from the outset to have national coverage. In England, this strategy was restricted to the publicly funded NHS, whereas in the USA it was to include both publicly and privately funded healthcare providers. Initial plans for national EHR coverage reflect policy recognition of the potential for secondary uses of national information relating to healthcare (e.g., for research, audit and planning). While the English and American approaches focus on secondary uses of national data in terms of major anticipated benefits, the Australian strategy has a somewhat different emphasis with its stated policy to empower citizens with a "person-controlled" EHR (Table 2). Importantly, in Australia the P-CEHR is planned to be optional. Australians are to choose whether to have a P-CEHR, what information it will contain and who may access that information, arguably reducing the potential for secondary uses benefits from Australian EHRs. In reviewing national policy objectives (Table 2) we note that patient care co-ordination and cost control are rarely explicitly stated as high level policy objectives. However, our experience in England indicates that these are frequently seen as major anticipated benefits of implementations at the local level [4].

\subsection{Economic Considerations}

All three national policies for EHR implementation are striking in their ambition. The theorised benefits of EHRs have been used to justify significant government investment, even in the more devolved approaches in the USA and Australia. Central government investment is only part of the cost of implementing national EHRs; additional implementation costs will be incurred at other levels, including local 


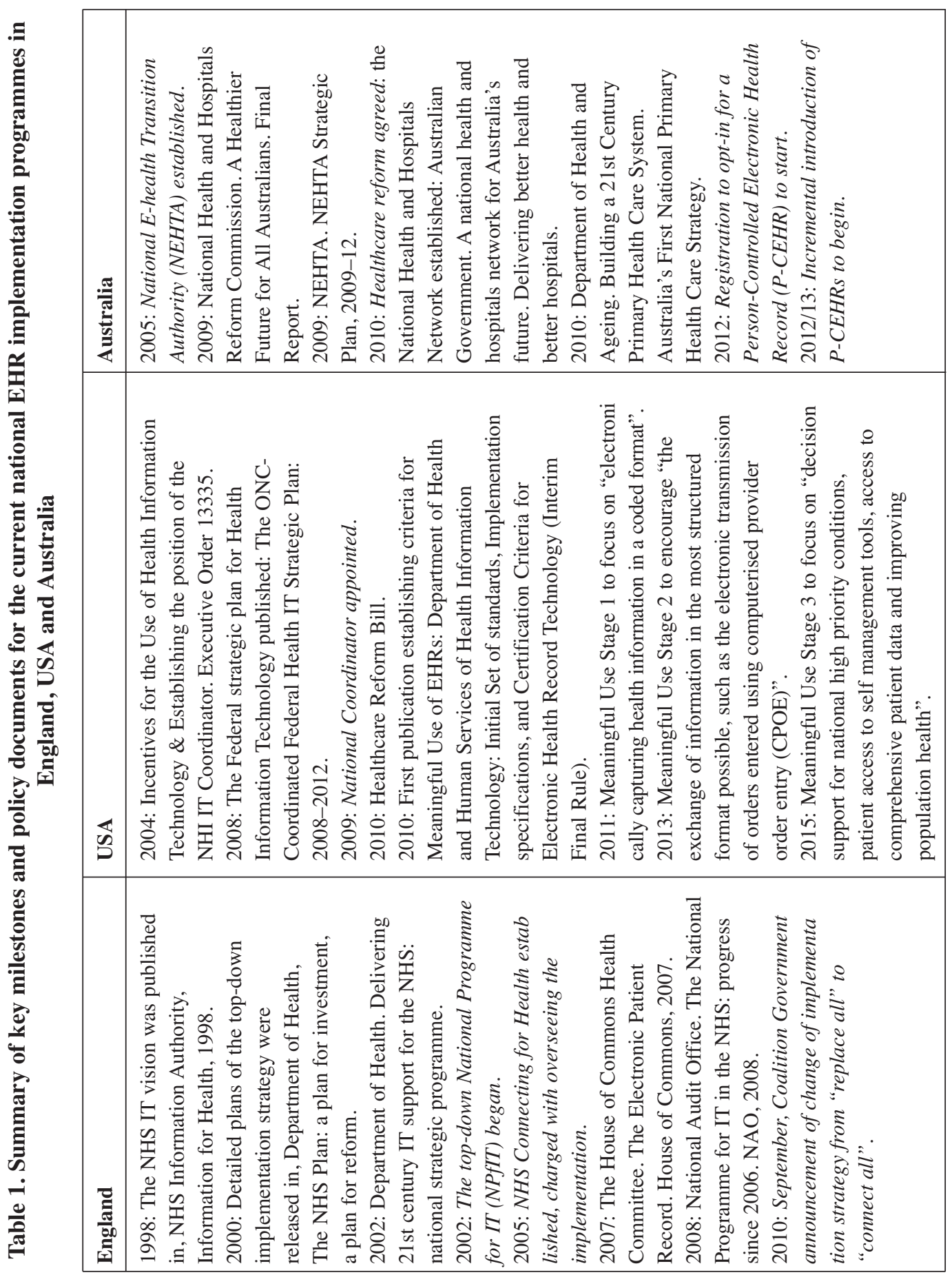


Table 2. Contrasts in stated national policy objectives among the three countries, England, the USA and Australia

\begin{tabular}{|c|c|}
\hline & National Objectives \\
\hline England & $\begin{array}{l}\text { Central data storage: } \\
\text { O National Spine, containing the basic capabilities of the system; } \\
\text { O National Network for the NHS (N3), allowing electronic data exchanges } \\
\text { across organisations; } \\
\text { O Personal Demographics Service (PDS), containing patients' } \\
\text { demographic details; } \\
\text { Images in Picture Archiving and Communication Systems (PACS); } \\
\text { Summary Care Record (SCR), which is held on the National Spine and } \\
\text { contains essential clinical information for emergencies; } \\
\text { Detailed Care Record (DCR), containing comprehensive clinical } \\
\text { information on individual patients, to be held and shared locally. } \\
\text { - Secondary Uses Service (SUS) for integration of data from different } \\
\text { sources and then making this available for audit, research and planning } \\
\text { purposes. }\end{array}$ \\
\hline USA & $\begin{array}{l}\text { Interoperability, functionality, utility and security: high-quality and efficient } \\
\text { patient-focused healthcare through the use of electronic health information. } \\
\text { - Secondary data usage for: } \\
\text { O Public health; } \\
\text { O Biomedical research; } \\
\text { O Quality improvement; } \\
\text { ○ Emergency preparedness. }\end{array}$ \\
\hline Australia & $\begin{array}{l}\text { Data sharing: critical patient information available when and where needed. } \\
\text { - Improvements in the safety and quality of healthcare, particularly by reduc- } \\
\text { ing medication errors and adverse drug events. } \\
\text { - Reduction of waste and inefficiency in the healthcare system, for example, } \\
\text { by avoiding repeated history taking and duplicating tests. } \\
\text { - Improvement in continuity of care - between providers and across } \\
\text { settings - and in health outcomes for patients. } \\
\text { - Greater information and control for patients to help them to self manage } \\
\text { their care. }\end{array}$ \\
\hline
\end{tabular}

investment at the level of individual healthcare organisations and practitioners. Central government investment is estimated at a per capita level for each country in Table 3. The estimates suggest notable differences; for example, the estimated central government spending per capita in England is some 20 times greater than in Australia. Differences may reflect such factors as the technology infrastructure in a country, population densities, geographical distances, differing functionalities of the EHR systems to be implemented and the planned timescales for nationwide deployments. Despite a variety of reasons for differences in government cost per capita at national 
Table 3. Estimated national government budget per capita

\begin{tabular}{|l|l|c|c|}
\hline & \multicolumn{1}{|c|}{$\begin{array}{c}\text { Estimated Government } \\
\text { Investment - Quoted } \\
\text { Budget Allocation }\end{array}$} & $\begin{array}{c}\text { Population } \\
\text { Mid-2008 Estimates }\end{array}$ & $\begin{array}{c}\text { Estimated Government } \\
\text { Investment per Capita } \\
\text { (Based on Highest } \\
\text { Estimated Budget) }\end{array}$ \\
\hline England & between $£ 6$ and $£ 12$ billion $[7]$ & $51,446,000[60]$ & $£ 233.25$ \\
\hline USA & $\$ 14$ and $\$ 28$ billion $[61]$ & $304,060,000[62]$ & $£ 60.78^{*}$ \\
\hline Australia & $\$ 466.7$ million & $21,431,800[62]$ & $£ 12.63^{* *}$ \\
\hline
\end{tabular}

Exchange rate: $(\mathrm{USA}) \$ 1.00=£ 0.66^{*}$

Exchange rate: (Aus) $\$ 1.00=£ 0.58 * *$

level, even the highest estimated costs might not be seen as overly expensive if they are justified in relation to the potential benefits of EHRs. It is interesting, therefore, that political debate and media scrutiny focus so strongly on the financial outlay of implementing these programmes. Given their anticipated long-term benefits, speculation about their value for money may be driven by the current lack of empirical evidence from successful implementations on a national scale. Further, public spending generally is increasingly scrutinised and politically contested given a difficult economic climate now in many countries.

\subsection{Progress to-date}

The progress of the national EHR implementations in England and the USA has been marked by changes since conception in terms of scope and implementation strategy, and in estimated budget allocations (Table 3 ). This is perhaps not surprising given the nature of large-scale change programmes, shifts in the respective political landscapes and financial pressures.

In England, governance structures have moved towards increased regional and local responsibility, while the national programme agency, NHS CFH, has recently changed from being an 'arm's length' government body by becoming integrated into the DH's Health Informatics Directorate [42; 43]. The scope of the national applications to deliver EHRs has also changed over time. This is in response to increasing recognition of the importance to NHS organisations of having flexibility in how their EHR systems are delivered and of being able to customise the software locally. It is also a response to financial pressures that have led to reductions in the numbers of systems to be deployed under the central contracts and in the scope of the solutions. For example, scaling back of some of the originally planned, more advanced functionalities was announced in early 2010 [44]. There has also been much public debate about data quality and security and about the EHR consent model, which has changed from an implied consent model to explicit consent due to pressure over time from independent academics and from professional bodies [45-48]. These developments have been in parallel with repeatedly missed, politically driven deployment deadlines in hospitals [49]. Although there have 
been some hospital-wide implementations of national EHR applications, particularly in London, they have often been accompanied by public debate about such problems as user engagement, whether the software is fit for purpose and questioning of the centralised, national approach [50]. To date, the sharing of records between healthcare settings has not been realised and advanced clinical functionalities, such as electronic prescribing with decision support, have not yet been implemented as part of the national solutions.

A new Coalition Government took office in 2010 and is carrying out a comprehensive spending review. This, coupled with the widely publicised delays with hospital deployments of EHRs, suggested further changes ahead, and these were confirmed in a government press release in September 2010 [51]. It stated that a centralised, top-down approach was "no longer required", although the centrally negotiated contracts would continue (alongside now allowing other suppliers to deliver EHR systems) and the national infrastructure for healthcare IT would be retained. This overt change in policy, moving from a top-down "replace all" approach to a middle-out "connect all" approach, may to some extent de-politicise the UK government's England-wide EHR initiative, by further devolving choice and responsibility and allowing EHR systems to emerge in ways that better suit local NHS needs.

Progress in the USA has been highly localised by the very nature of the more bottom-up approach. Examples of where progress has been made and shared are Kaiser Permanente [52] and the Veterans Health Information Systems and Technology Architecture (VistA) system in the Department of Veterans Affairs (VA) [53]. With an annual budget of $\$ 36$ billion, and supporting care for over five million individuals each year [54], VistA is the largest, most broadly implemented health service system in the USA. It is composed of numerous applications, two of which markedly advanced the evolution of the system. The first, the Computerised Patient Record System (CPRS), integrates multiple existing programmes to display timely, patient-centric information. It facilitates a shift from paper to computer-based records charting, providing a single interface for users to view pharmacy data, lab results and consultations, and to place orders [53]. The second, Bar Code Medication Administration (BCMA), is a bedside application. From 1999, the VA sought to address prescribing errors, such as misidentification of the patient, incorrect medication, wrong administration times and transcription errors [55], by developing an application that requires nurses to scan the patient wristband, the packaged medication and their own employee IT card to administer a medicine. End-users at VA sites were encouraged to give feedback to national developers, and software developed progressively at local sites was often shared between sites [56]. A recent study found that VistA was a highly functional and widely adopted system, for both hospitals and physicians' offices [57].

In the USA, initiatives such as VistA claim to have delivered organisation-wide benefits. The challenge now is compliance with the national Meaningful Use Criteria (Table 1). The introduction of centrally funded incentives to promote nationwide interoperability is evidence of central government influencing local healthcare providers in order to achieve national policy objectives. Thus the initially bottom-up approach in the USA increasingly combines roles for central government and local healthcare providers, that is, it too may be categorised as moving towards a middle-out approach. 
Australia is only at the starting blocks in its current, middle-out national EHR programme, with an expected wait of at least two years before the first P-CEHRs come into use. Legislation was passed last summer to approve plans to allocate universal, unique Health Identifier numbers to all individuals, to healthcare providers and to healthcare organisations. The ability to identify patients reliably and correctly to match a patient to his or her healthcare information is seen as an essential underpinning for the proposed EHR system. The patient Health Identifier is a 16-digit number linked only to demographic information. The next steps will be a staged rollout of P-CEHRs, accompanied by system evaluations, at a selection of early implementation sites. It is anticipated that the first implementations will focus on public hospital patients who have a greater need for healthcare services, such as mothers and babies, indigenous and older Australians and individuals with long-term conditions.

Having a single national body, NEHTA, to work on national standards in collaboration with P-CEHR stakeholders in advance of any implementation may prove an important advantage, as could the national policy to take an incremental approach with evaluations of pilot sites. Nonetheless, Australia is unlikely to be immune from public and health professionals' concerns about data privacy, confidentiality and security in new P-CEHR systems and from at least some opposition to introducing a universal Health Identifier System for the first time. The Commonwealth government has committed to making a significant investment in nationwide P-CEHRs. Investment will also be required at state level; there may be variable, local resource and capacity difficulties to be overcome. Most importantly, given that a national, middle-out approach to implementing and adopting P-CEHRs has yet to be accomplished anywhere in the world, the quality and extent of healthcare data exchange between multiple, diverse local systems in practice remains to be seen.

\section{DISCUSSION}

The overview presented here supports Coiera's [6] conceptualisation of national EHR implementation approaches as being bottom-up, middle-out or top-down, and his assertion that an initially bottom-up or top-down strategy may evolve into a middle-out one over time. In going beyond a descriptive account of the deployment experiences in each of three exemplar countries, we have sought to contextualise and understand the initial procurement and implementation strategy decisions, and subsequent adjustments to the approaches. Our review identifies significant changes of approach since inception in two of the three national EHR programmes considered here. England has migrated to the middle-out from an initially top-down strategy and the USA is partially migrating towards middle-out from an initially bottom-up strategy. The third country, Australia, is to embark on a middle-out approach from the start, but this follows earlier healthcare IT initiatives in that country in which a more top-down approach had already been tried. In all three cases, the current approaches may now be described in Coiera's terms as broadly middle-out.

The rationale for the approach that was initially chosen in each country related to an array of contextual factors, including the structure, funding and ethos of the country's healthcare system, past experience, available technologies, the existing IT infrastructure 
and resources and, importantly, domestic political and economic factors. Healthcare and healthcare reform are inherently political; shorter-term changes in government and in the domestic economy are always likely to influence long-term national healthcare IT strategies. Our review has shown that despite quite different national contexts in England, the USA and Australia, the broader political aims underlying the rationale for implementing national EHR systems were very similar. Each hopes to use IT-enabled change to improve the quality, efficiency and sustainability of the country's healthcare $[7,8]$. Within that broad aim, different countries were seen to place different emphasis on various hoped-for benefits in their stated national policy objectives. We suggest that even allowing for disparities in the estimated per capita investments by governments, if the anticipated benefits of EHR systems were to be achieved, these investments could ultimately be perceived as good value for money. The cautionary note is, however, that it is not yet clear that these potential benefits will be realised, nor how best they might be measured. In the meantime, the lack of robust empirical evidence for benefits from national EHR systems leaves ample room for speculation, supposition and, in some cases, opposition.

Evolution of the initial approaches was clearly evident in England and in the USA. The changes were most striking in England where the economies of scale promised by centrally procured, standardised systems have proved largely elusive and, after eight years of struggling to deliver EHR systems under the constraints of the initial policy, the top-down strategy has now officially been abandoned. An important factor in the incremental changes, culminating in the official change of policy, was that the NHS in England consists of multiple, diverse and partially autonomous organisations with varying resources and IT capabilities; the "national" health service is far less uniform and amenable to central directives on healthcare IT than its name might suggest. The political rationale for changing the implementation approach appears to be pragmatic. It may also reflect the fact that the government now in office and announcing the official policy change is different from the government that instigated the top-down programme.

In the USA, the introduction of middle-out elements to a broadly bottom-up approach also appears to be based on pragmatism. While the diversity and autonomy of multiple healthcare providers were recognised from the outset here, and organisations such as the VA and Kaiser Permanente offer examples of pockets of good progress with EHR implementation, it has been recognised that to achieve national connectivity, some national direction and support is also needed, hence the introduction of Meaningful Use Criteria and financial incentives for healthcare providers. Nonetheless, and despite the English experience of failing to meet politically driven, unrealistic deployment deadlines for EHRs in hospitals, the timescale in which USA healthcare providers are expected to meet the EHR Meaningful Use Criteria is still very ambitious.

\section{CONCLUSION}

While we report early evidence of international convergence on broadly middle-out approaches here, there is no empirical evidence to support advocating a middle-out approach in relation to large-scale national implementations of EHR systems. Rather, 
this review of initial implementation approaches and developments in England, the USA and Australia suggests that in the face of intractable difficulties with top-down and bottom-up approaches, for local acceptance and for national connectivity, a middle-out strategy might be acknowledged as 'the best bet'. This may be the case notwithstanding starting and ongoing differences in individual countries' political and economic contexts, which are themselves in a state of continual flux. Given the negotiated nature and ambitious scale of these inevitably slow, IT-enabled transformations of healthcare systems, an evolutionary approach, and an evolution of approach, would seem an optimum strategy.

It will, we acknowledge, be many years yet before we can draw firm, evidence-based conclusions about the implementations and resultant benefits (and harms), both anticipated and unanticipated, of the three national EHR systems reviewed in this paper. Despite this note of caution, there is, we believe, great value in carefully considering any preliminary lessons that may be inferred from early, international experiences of implementing large-scale, national EHR systems. Disseminating lessons learnt across international boundaries is vital given the expense, disruption and potential benefits of IT-enabled healthcare reform. Here, we have identified movement towards middle-out approaches in three countries, despite very different national contexts, a tendency towards (overly) ambitious expectations about the timescale in which national EHR systems can be implemented (England and the USA), and the shared lack of national evidence on realising the theorised benefits that were the rationale for starting the programmes. Preliminary conclusions from comparing and contrasting these three countries are that, notwithstanding different domestic contexts, adopting a form of middle-out approach from the start may be an advisable initial strategy for countries considering implementing national EHR systems. There is also a clear need for work that focuses on building an evidence base for the benefits of national EHR implementations $[58,59]$. Evaluating large-scale EHR programmes and developing methods to measure their theorised benefits are certainly complicated by the shifting domestic contexts in which implementations take place, by implementation approaches that evolve over time, by changing consequences (benefits and harms) of sociotechnical change programmes over time, and by the lack of clarity about when an implementation can be said to have 'ended'. Nonetheless, the need internationally for reliable evidence of national benefit, and thereby justification for public expenditure, requires to be addressed.

We hope that colleagues will extend these first reflections on three countries' attempts to deliver national EHR systems and over time build on this early effort to identify and share lessons inferred from international comparisons of approaches.

\section{ACKNOWLEDGEMENTS}

We gratefully acknowledge the support of the NHS Connecting for Health Evaluation Programme (grants 001, 005, 009 and 010) and our colleagues who work with us on these evaluations. KC is supported by a studentship from the Medical Research Council. We would also like to thank the reviewers for their helpful comments on earlier drafts of this paper. 


\section{REFERENCES}

[1] Massaro TA. Introducing physician order entry at a major academic medical center: 1. Impact on organizational culture and behaviour. Acad Med 1993; 68: 20-25.

[2] Sicotte C, Denis JL, Lehoux P. The Computer Based Patient Record: A Strategic Issue in Process Innovation. Journal of Medical Systems 1998; 22(6): 431-443.

[3] Southon G, Sauer C, Dampney K. Lessons from a failed information systems initiative: issues for complex organisations. Int J Med Inform 1999; 55(1): 33-46.

[4] Robertson A, Cresswell K. Takian A, Petrakaki D, Crowe S. Cornford T, Barber N, Avery A, Fernando B, Jacklin A, Prescott R, Klecun E, Paton J, Lichtner V, Quinn C, Ali M, Morrison Z, Jani Y, Waring J, Marsden K, Sheikh A. Implementation and adoption of nationwide electronic health records in secondary care in England: qualitative analysis of interim results from a prospective national evaluation. BMJ 2010; 341: c4564 doi: 10.1136/bmj.c4564.

[5] Cresswell KM, Sheikh A. The NHS Care Record Service (NHS CRS): recommendations from the literature on successful implementation and adoption. Inform Prim Care. 2009; 17(3): 161-4.

[6] Coiera E. Building a National Health IT System from the middle out. J Am Med Inform Assoc 2009; 16(3): 271-273.

[7] Car J, Anandan C, Black A, Cresswell K, Pagliari C, McKinstry B et al. The Impact of eHealth on the Quality \& Safety of Healthcare - A systematic overview and synthesis of the literature. Report for the NHS Connecting for Health Evaluation Programme. 2008.

[8] Majeed A, Car J, Sheikh A. Accuracy and completeness of electronic patient records in primary care. Family Practice 2008; 25(4): 213-214.

[9] Adler-Milstein J, Bates DW. Paperless healthcare: Progress and challenges of an IT-enabled healthcare system. Business Horizons 2003; 53(2): 119-130.

[10] Berg M. Implementing information systems in health care organizations: myths and challenges. International Journal of Medical Informatics 2001; 64(2-3): 143-156.

[11] Classen D, Bates DW, Denham CR. Meaningful Use of Computerized Prescriber Order Entry. Journal of Patient Safety 2010; 6(1).

[12] Greenhalgh T, Stramer K, Bratan T, Byrne E, Russell J, Hinder S et al. The Devil's in the Detail: Final Report of the independent evaluation of the Summary Care Record and HealthSpace programmes. 2010. London, University College London.

[13] Greenhalgh T, Stramer K, Bratan T, Byrne E, Mohammad Y, Russell J. Introduction of shared electronic records: multi-site case study using diffusion of innovation theory. BMJ 2008; 337(oct23_1): a1786.

[14] Boonstra A, Broekhuis M. Barriers to the acceptance of electronic medical records by physicians From systematic review to taxonomy and interventions. BMC Health Services Research 2010; 10: 231.

[15] Protti D, Bowden T, Johansen I. Adoption of information technology in primary care physician offices in New Zealand and Denmark, part 1: healthcare system comparisons. Inform Prim Care 2008; 16(3): $183-187$.

[16] Protti D, Bowden T, Johansen I. Adoption of information technology in primary care physician offices in New Zealand and Denmark, part 2: historical comparisons. Inform Prim Care 2008; 16(3): 189-193.

[17] Protti D, Bowden T, Johansen I. Adoption of information technology in primary care physician offices in New Zealand and Denmark, Part 3: Medical record environment comparisons. Inform Prim Care 2008; 16(4): 285-290.

[18] Protti D, Bowden T, Johansen I. Adoption of information technology in primary care physician offices in New Zealand and Denmark, Part 4: Benefits comparisons. Inform Prim Care 2008; 16(4): 291-296.

[19] Protti D, Bowden T, Johansen I. Adoption of information technology in primary care physician offices in New Zealand and Denmark, part 5: final comparisons. Inform Prim Care 2009; 17(1): 17-22.

[20] Protti D, Johansen I, Perez-Torres F. Comparing the application of Health Information Technology in primary care in Denmark and Andalucia, Spain. Int J Med Inform 2009; 78(4): 270-283. 
[21] Canada's electronic health records initiative stalled by federal funding freeze. Canadian Medical Association, 2010, doi: 10.1503/cmaj.109-3183. (last accessed 21/06/10).

[22] Office of the National Coordinator for Health Information Technology. Health Information Technology: Initial Set of standards, Implementation specifications, and Certification Criteria for Electronic Health Record Technology (Interim Final Rule). Department of Health and Human Services. Available from: http://www.scribd.com/doc/26297852/Health-Information-Technology-Initial-Set-of-StandardsImplementation-Specifications-and-Certification-Criteria (Accessed on 18.06.10). 2009.

[23] Office of the National Coordinator for Health Information Technology. The ONC-Coordinated Federal Health IT Strategic Plan: 2008-2012. Department of Health and Human Services: 2008 Available from: http://www.hhs.gov/healthit/resources/HITStrategicPlan.pdf (last accessed 18.06.10). 2010.

[24] Certification Commission for Health Information Technology Website. Available from: http://www.cchit.org/ (last accessed 18.06.10). 2010.

[25] The Office of the National Coordinator for Health Information Technology. Department of Health and Human Services: 2010. Available from: http://healthit.hhs.gov (last accessed 18.06.10). 2010.

[26] Pollack R, Executive Vice President, American Hospital Association. Available from: www.aha.org/aha/letter/2010/100315-cl-EHRIFR.pdf. 2010.

[27] Wilson CB, American Medical Association. Available from: http://www.ama-assn.org/ama/ pub/news/speeches.shtml (last accessed: 15.10.10). 2008.

[28] Jha AK, DesRoches CM, Kravovec PD, Joshi MS. A Progress Report on Electronic Health Records in U.S. Hospitals. Health Affairs, doi: 10.1377/hlthaff.2010.0502.

[29] Australian Government. A national health and hospitals network for Australia's future. Delivering better health and better hospitals. Available at: http://www.health.gov.au/internet/yourhealth/ publishing.nsf/Content/report-redbook/\$File/HRT_report3.pdf. 2010.

[30] Department of Health and Ageing. Building a 21st Century Primary Health Care System. Australia's First National Primary Health Care Strategy. 2010. Available at: http://www.yourhealth.gov.au/ internet/yourhealth/publishing.nsf/Content/550436A8DA6839ECCA25771B00220E23/\$File/6552\% 20NPHC\%201205.pdf. 2010.

[31] NEHTA. NEHTA Strategic Plan, 2009-12. Available at: http://www.nehta.gov.au/about-us/strategy (last accessed 26.06.10). 2009.

[32] Harrison M. Implementing change in health systems. London: Sage Publications, 2004.

[33] Hamilton S, Huby G, Tierney A, Powell A, Kielmann T, Sheikh A et al. Mind the gap between policy imperatives and service provision: a qualitative study of the process of respiratory service development in England and Wales. BMC Health Services Research 2008; 8(1): 248.

[34] Department of Health. Equity and excellence: Liberating the NHS. 2010. The Stationery Office.

[35] World Health Organisation. World Health Statistics 2009. Available from http://www.who.int/whosis/ whostat/2009/en/index.html (last accessed 24.06.10). 2009.

[36] DeNavas-Walt C, Proctor BD, Smith JC. Income, Poverty, and Health Insurance Coverage in the United States: 2007 U.S. Department of Commerce Economics and Statistics Administration, U.S. Census Bureau. Available at: http://www.census.gov/prod/2008pubs/p60-235.pdf (last accessed 24.06.10). 2008.

[37] MacAskill E. Barack Obama's healthcare bill passed by Congress. Available at: http://www. guardian.co.uk/world/2010/mar/22/us-healthcare-bill-passes-congress (last accessed 29.11.10). 2010.

[38] Taylor DH, Jr. What price for-profit hospitals? CMAJ 2002; 166(11): 1418-1419.

[39] Devereaux PJ, Choi PTL, Lacchetti C, Weaver B, Schunemann HJ, Haines T et al. A systematic review and meta-analysis of studies comparing mortality rates of private for-profit and private not-for-profit hospitals. CMAJ 2002; 166(11): 1399-1406.

[40] Devereaux PJ, Heels-Ansdell D, Lacchetti C, Haines T, Burns KEA, Cook DJ et al. Payments for care at private for-profit and private not-for-profit hospitals: a systematic review and meta-analysis. CMAJ 2004; 170(12): 1817-1824.

[41] Institute of Medicine. The computer-based patient record: An essential technology for health care. 1991. Washington, D.C., National Academy Press. 
[42] SmartHealthcare. Informatics Directorate takes over from CfH. http://www.smarthealthcare.com/ informatics-directorate-05mar09 last accessed 13.09.10. 2010.

[43] Young T. NHS IT to be reorganised. http://www.computing.co.uk/computing/news/2238260/nhsreorganised last accessed 13.09.10. 2009.

[44] Hoeksma J. Bacon says 'prove value of NPfIT deals'. http://www.ehiprimarycare.com/news/5767/ bacon_says_\%27prove_value_of_npfit_deals\%27. last accessed 13.09.10.2010.

[45] Barr F. ICO issues guidance on SCR opt-outs. http://www.ehiprimarycare.com/news/6122/ ico_issues_guidance_on_scr_opt-outs last accessed 13.09.10.2010.

[46] eHealth Insider. Urgent review of SCR consent model recommended. http://www.e-health-insider. com/news/3720/urgent_review_of_scr_consent_model_recommended last accessed 13.09.10. 2008 .

[47] Greenhalgh T, Wood GW, Bratan T, Stramer K, Hinder S. Patients attitudes to the summary care record and HealthSpace: qualitative study. BMJ 2008; 336(7656): 1290-1295.

[48] Greenhalgh T, Stramer K, Bratan T, Byrne E, Russell J, Potts HWW. Adoption and non-adoption of a shared electronic summary record in England: a mixed-method case study. BMJ 2010; 340(jun16_4): c3111.

[49] SmartHealthcare. NPfIT goes to the country. http://www.smarthealthcare.com/england-patient-records last accessed 13.09.10. 2010.

[50] Collins T. Cerner and BT in Royal Free NPfIT rescue plan - but a setback for NPfIT vision of standard systems. http://www.computerweekly.com/blogs/tony_collins/2008/11/new-setback-for-npfit-visiono.html last accessed 13.09.10. 2008.

[51] Department of Health. The future of the National Programme for IT. http://www.dh.gov.uk/en/ MediaCentre/Pressreleases/DH_119293 last accessed: 04.10.2010. 2010.

[52] Kaiser Permanente. Connected for Health: using electronic health records to transform care delivery. San Francisco: Jossey-Bass, 2010.

[53] Brown SH, Lincoln MJ, Groen PJ, Kolodner RM. VistA-U.S. Department of Veterans Affairs national-scale HIS. Int J Med Inform 2003; 69(2-3): 135-156.

[54] Congressional Budget Office. The Health Care System for Veterans: An interim Report 2007. Available at: http://www.cbo.gov/ftpdocs/88xx/doc8892/12-21-VA_Healthcare.pdf (last accessed 19.06.10). 2007.

[55] Johnson C, Carlson R, Tucker C, Willette C. Using BCMA software to improve patient safety in veterans administration medical centers. Journal of Healthcare Information Management 2002; 16(1).

[56] Department of Health and Ageing. Health Identifiers Service. http://www.health.gov.au/internet/main/ publishing.nsf/Content/5137E02F08412623CA2575ED008386B8/\$File/20100202\%20HI\%20SERVI CE\%20-\%20FAQs.pdf last accessed 13.09.10. 2010.

[57] Byrne CM, Mercincavage LM, Pan EC, Vincent AG, Johnston DS, Middleton B. The value from investments in health information technology at the U.S. Department of Veterans Affairs. Health Aff (Millwood) 2010; 29(4): 629-638.

[58] Lilford RJ, Foster J, Pringle M (2009) 'Evaluating eHealth: How to Make Evaluation More Methodologically Robust'. PLoS Med 6(11): e1000186. doi: 10.1371/journal.pmed.1000186.

[59] Lilford, RJ., Chilton, P., Hemming, K., Girling, A., Taylor, C., and Barach, P. (2010) 'Evaluating policy and service interventions: framework to guide selection and interpretation of study end points'. British Medical Journal; 341: c4413, doi: 10.1136/bmj.c4413.

[60] Office for National Statistics. Population Estimates. http://www.statistics.gov.uk/cci/nugget.asp?id=6 last accessed 21.06.10. 2010.

[61] American Hospital Association. HIT Incentive Payment Program: Definition of 'Meaningful Use' Available from: http://www.aha.org/aha/content/2010/pdf/10-ib-def-meaning-use.pdf last accessed 19.06.10. 2010 .

[62] Worldbank databank. World development indicators. http://data.worldbank.org/indicator/ SP.POP.TOTL?cid=GPD_1 last accessed 21.06.10. 2010. 



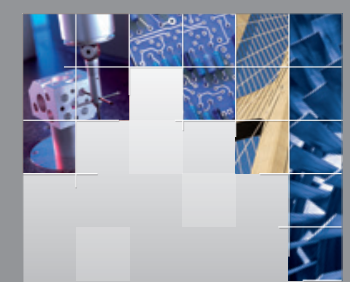

\section{Enfincering}
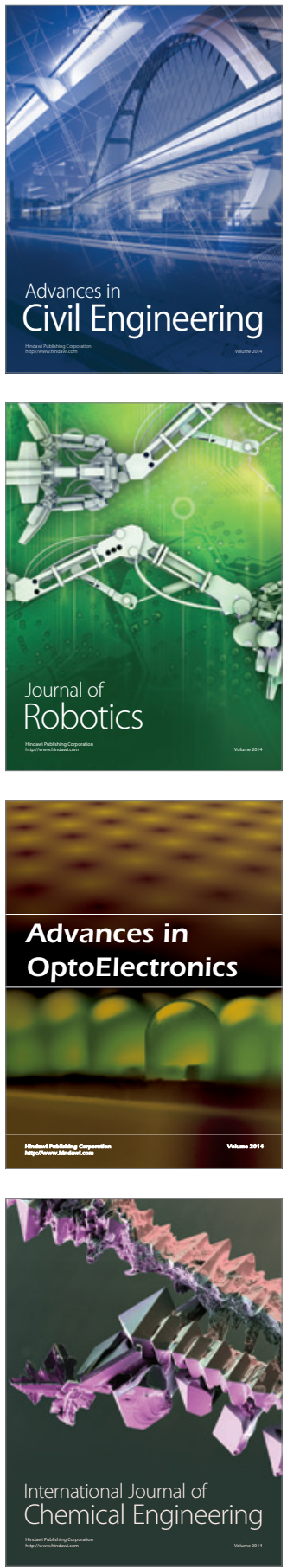

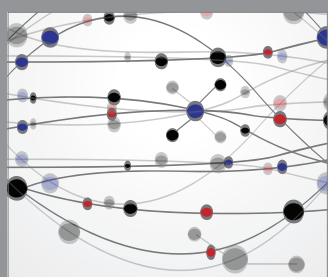

The Scientific World Journal

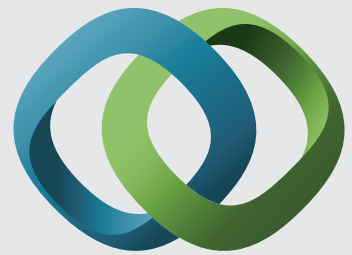

\section{Hindawi}

Submit your manuscripts at

http://www.hindawi.com
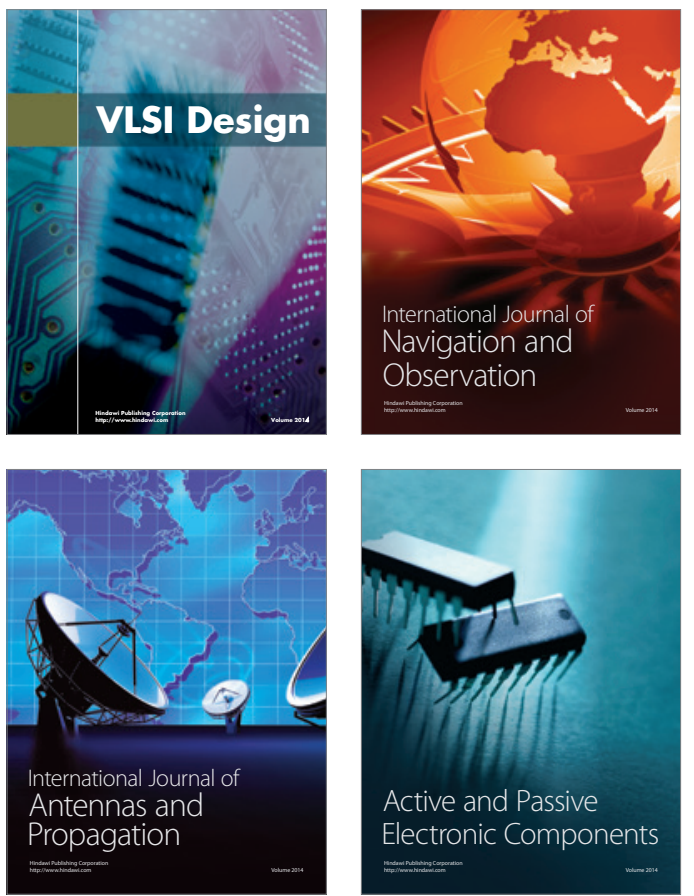
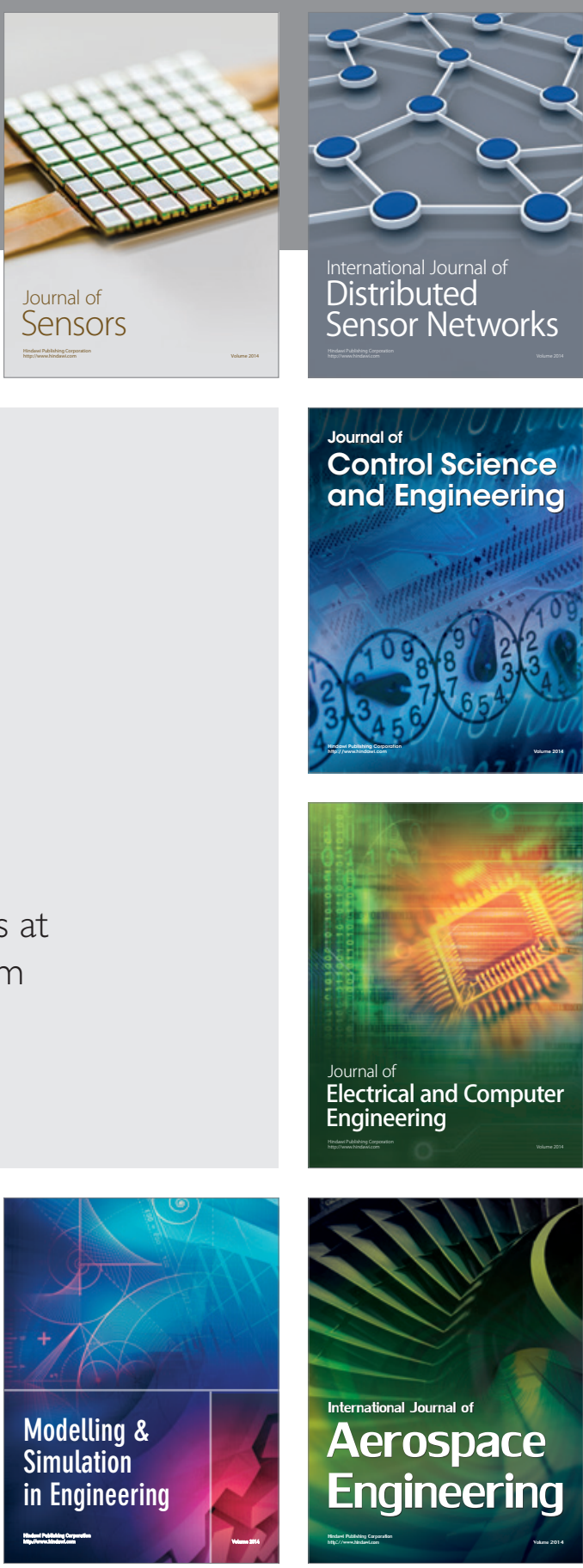

International Journal of

Distributed

Sensor Networks

Journal of

Control Science

and Engineering
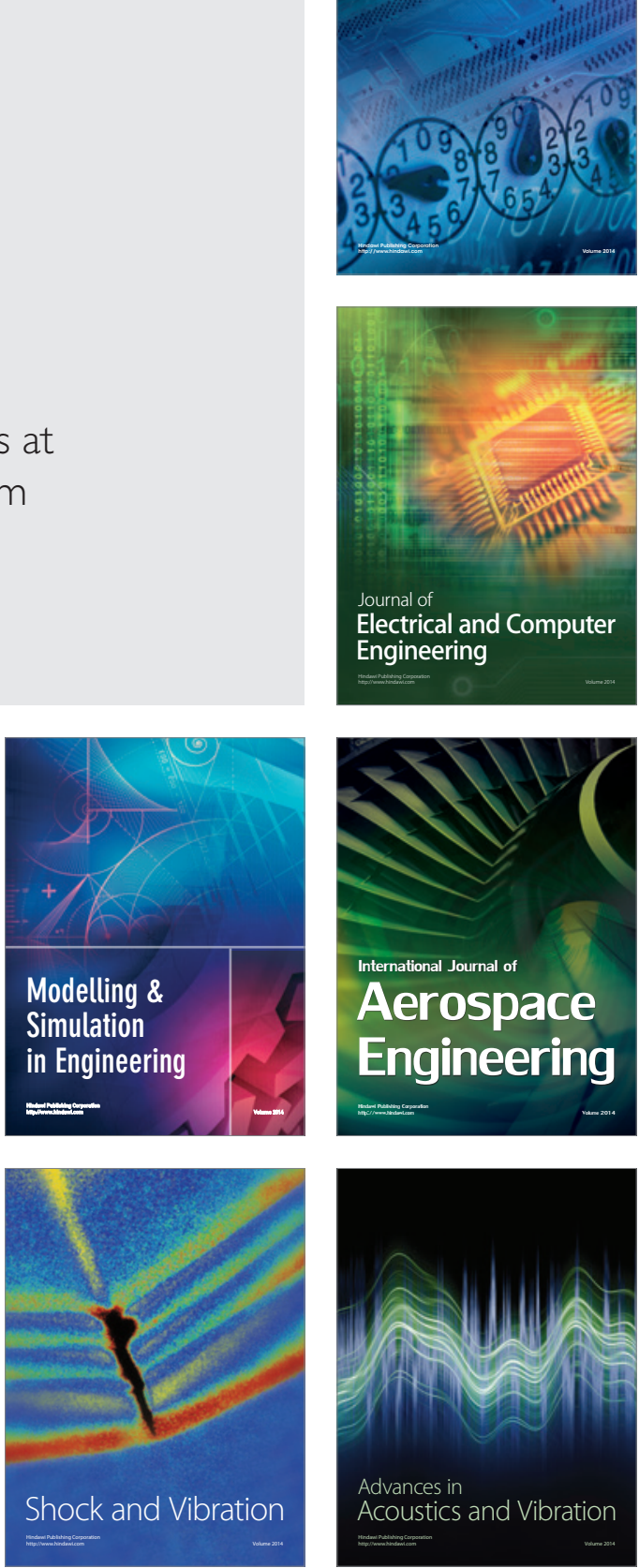